\title{
Multimode/Multifrequency Low Frequency Airborne Radar Design
}

\author{
Sandra Costanzo, ${ }^{1}$ Giuseppe Di Massa, ${ }^{1}$ Antonio Costanzo, ${ }^{1}$ Antonio Borgia, ${ }^{1}$ \\ Claudio Papa, ${ }^{2}$ Giovanni Alberti, ${ }^{2}$ Giuseppe Salzillo, ${ }^{2}$ Gianfranco Palmese, ${ }^{2}$ \\ Dario Califano, ${ }^{2}$ Luca Ciofanello, ${ }^{2}$ Maria Daniele, ${ }^{2}$ Claudia Facchinetti, ${ }^{3}$ \\ Francesco Longo, ${ }^{3}$ and Roberto Formaro ${ }^{3}$ \\ ${ }^{1}$ Dipartimento di Ingegneria Informatica, Modellistica, Elettronica e Sistemistica, Università della Calabria, 87036 Rende, Italy \\ ${ }^{2}$ Consortium of Research on Advanced Remote Sensing Systems (CO.RI.S.T.A.), 80125 Napoli, Italy \\ ${ }^{3}$ Italian Space Agency (ASI), Rome, Italy
}

Correspondence should be addressed to Sandra Costanzo; costanzo@deis.unical.it

Received 29 May 2013; Revised 16 September 2013; Accepted 17 September 2013

Academic Editor: Marcelo Sampaio de Alencar

Copyright (C) 2013 Sandra Costanzo et al. This is an open access article distributed under the Creative Commons Attribution License, which permits unrestricted use, distribution, and reproduction in any medium, provided the original work is properly cited.

\begin{abstract}
This work deals with the design of multimode/multifrequency airborne radar suitable for imaging and subsurface sounding. The system operates at relatively low frequencies in the band ranging from VHF to UHF. It is able to work in two different modalities: (i) nadir-looking sounder in the VHF band $(163 \mathrm{MHz})$ and (ii) side-looking imager (SAR) in the UHF band with two channels at $450 \mathrm{MHz}$ and $860 \mathrm{MHz}$. The radar has been completely designed by CO.Ri.S.T.A. for what concerns the RF and the electronic aspect, and by the University of Calabria for what concerns the design, realization, and test of SAR antennas. The radar has been installed on a civil helicopter and its operation has been validated in flight in both sounder and imager modality. Preliminary surveys have been carried out over different areas of Campania region, South Italy.
\end{abstract}

\section{Introduction}

In recent years, great interest has been devoted to the development of airborne radars working in the frequency range from VHF to UHF bands (e.g., see [1-4]). The combination of low frequencies with high relative bandwidth of such systems allows several military and civilian applications. According to Table 1, these range from forestry applications, biomass measuring, and monitoring, archaeological and geological exploration, glaciers investigation, and detection and localization of buried targets. In addition, their extension to noncivil applications concerns subsurface target detection and foliage penetration. The development of this type of systems entails technological and scientific efforts in the design of antennas, low noise amplifiers, band-pass filters, and digital receiver technology, as well as in the field of dataprocessing algorithms.
In this framework, the Italian Space Agency (ASI) has promoted the development of a new multifunction/multimode airborne radar able to operate as a nadir-looking sounder in the VHF band and as side-looking imager in the UHF band. On one side, it constitutes a "proof of concept" for next Earth observation and planetary exploration space missions; from another perspective, the system can be seen as a validation tool for civil and non-low frequency radar terrestrial diagnostics, imaging, and monitoring applications. The radar system has been conceived and funded by ASI to be a growing laboratory to experiment and asses potentialities of low frequency radar bands (up to about $1 \mathrm{GHz}$ ). To this aim, three working frequency values have been chosen, namely, low, middle, and high ones. The low one $(163 \mathrm{MHz})$, up to now, has been used in sounder mode, since ASI has a strong heritage in such systems for planetary exploration (MARSIS and SHARAD for Mars and future RIME for 
TABLE 1: Applications for low frequency airborne radars.

\begin{tabular}{lll}
\hline Application & Scope & Observation technique \\
\hline Forest classification and biomass retrieval & $\begin{array}{l}\text { Biosphere and bioclimatology studies, } \\
\text { especially for terrestrial carbon cycle } \\
\text { evaluation }\end{array}$ & Side-looking SAR \\
\hline Ice sheets sounding & $\begin{array}{l}\text { Glaciology studies to better describe ice } \\
\text { sheet dynamics, which is connected with } \\
\text { climate changes and sea level modifications }\end{array}$ & $\begin{array}{l}\text { Nadir-looking SAR or cross-track } \\
\text { interferometric SAR }\end{array}$ \\
\hline $\begin{array}{l}\text { Subsurface geomorphology, soil moisture } \\
\text { estimation, permafrost, and sea salinity analysis }\end{array}$ & Climate modeling & $\begin{array}{l}\text { Side-looking SAR (subsurface analyses } \\
\text { may require nadir-pointing geometry) }\end{array}$ \\
\hline Target detection in forest areas & Military application & Side-looking SAR \\
\hline
\end{tabular}

Jovian icy moon), but it can also be used in off-nadir configuration as imager. On the contrary, the middle and high frequencies $(450 \mathrm{MHz}$ and $860 \mathrm{MHz}$ ) are currently used in SAR configuration, but pointing the antennas at nadir; also, sounder configuration is in principle possible.

Three frequencies packed into one system mean to observe the same scene at different penetration depths, and that is very powerful in tomographic applications.

Of course, this implies to have a radar system very flexible, easy to be installed on board of small airborne platform, easy to be configured in different modalities, and with low operational costs. These key points have driven the present radar development and, in our opinion, represent the actual novelty of the proposed instrument.

The research consortium CO.RI.S.T.A. was in charge of the design, realization, and in flight validation of the system. In particular, the development stage has benefited from the expertise made jointly by ASI and CO.RI.S.T.A. in a recent project concerning the design and realization of the SORA, a sounder installed on a stratospherical balloon. This was deployed during a mission on Svalbard Islands on 2009 with the aim to carry out a very large scale investigation of the glaciers stratigraphy. In the framework of the system development, the SAR antenna design and implementation are the responsibility of University of Calabria as CO.RI.S.T.A. subcontractor.

In this work, we present the complete radar system design, including the SAR antennas, and the full guidelines that have driven the system realization.

The paper is organized as follows. Section 2 describes the main features of the radar system. Section 3 deals with the description of the design and test of SAR antennas. Section 4 discusses the results of a first measurement campaign. Finally, conclusions and future works are outlined in Section 5.

\section{Radar System Description}

The radar exploits three different frequency bands: VHF channel with center frequency at $163 \mathrm{MHz}$ and two UHF channels with center frequency at $450 \mathrm{MHz}$ and $860 \mathrm{MHz}$, respectively, in such a way to achieve both subsurface and SAR imaging capabilities. The sounder operates with a $163 \mathrm{MHz}$ carrier and the effective bandwidth is equal to $10 \mathrm{MHz}$. As regards the SAR modality, two frequency

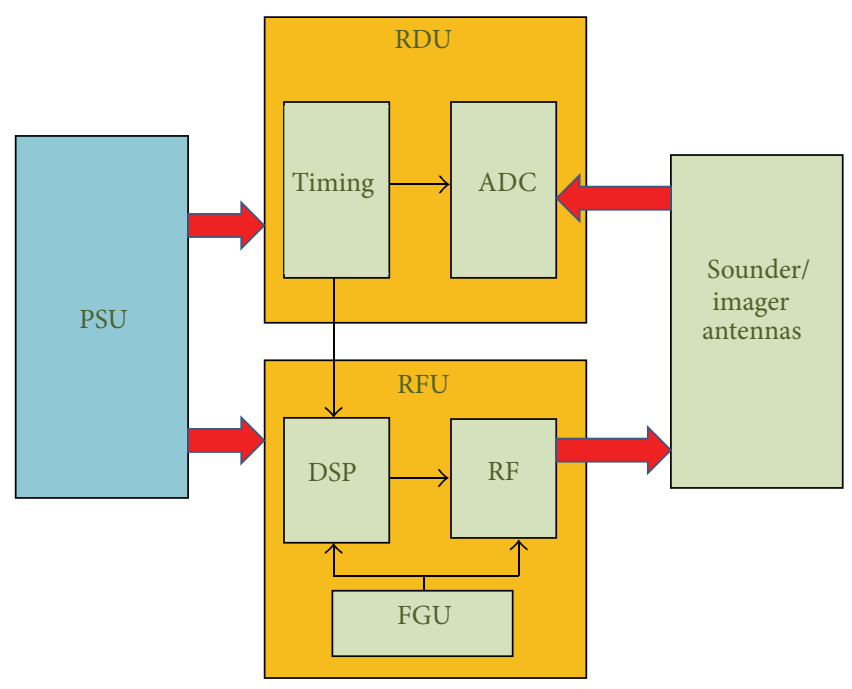

FigURE 1: Block diagram of radar system.

ranges are employed to obtain two imagers with lower and higher resolution. The lower resolution SAR (SAR-Low) imager works at $450 \mathrm{MHz}$ with a $40 \mathrm{MHz}$ bandwidth, whereas the higher resolution SAR (SAR-High) imager operates at $860 \mathrm{MHz}$ with a bandwidth of $80 \mathrm{MHz}$.

In both the sounder and imager modalities, a linear frequency modulated signal is transmitted, where the bandwidth is synthesized in the imager mode by a stepped chirp and each bandwidth step is equal to $10 \mathrm{MHz}$, in order to achieve higher resolution products.

The entire system can be schematized as built by three main blocks (see Figure 1): Radar Digital Unit (RDU), Radio Frequency Unit (RFU), and Power supply Unit (PSU). The RDU is in charge of the parameters setting, timing generation, and data handling. It is a full programmable digital unit comprising the Analog to Digital Converter (ADC) and the data storage unit. The RFU embeds the Frequency Generation Unit (FGU), having the task to generate all synchronisms and RF signals, and the DSP, which generates the Low Frequency Modulated (LFM) signal chirp by means of digital synthesis. The PSU provides the power supply to the whole system by external $28 \mathrm{~V}$ DC voltage. 


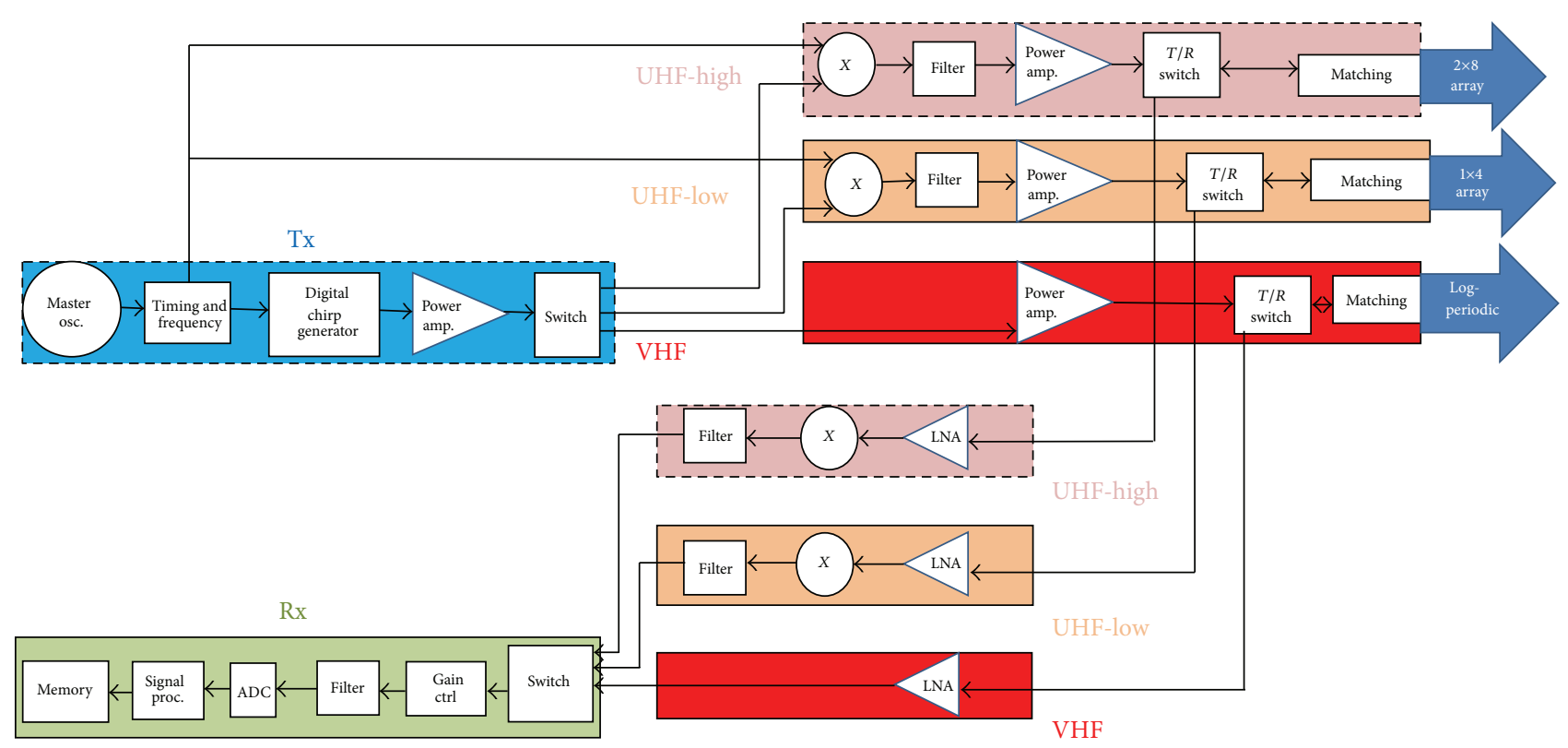

FIGURE 2: General system architecture.

The general architecture of the system is depicted in Figure 2. As it can be seen, the design is conceived so that most building blocks are shared by sounder and imager functionalities. In particular, base band signal generation, base band data sampling, and data handling are common to both sounder and imager operational mode. This represents the main feature of the entire system. The great advantage stands in the utilization of the same ADC, which is possible due to the adoption of an undersampling technique.

The system has been designed to be very flexible as far as timing and configuration parameters are concerned. Stepped frequencies and bandwidth are generated by means of DDS technology and all relevant parameters can be configured by the user before the flight. Therefore, the system has the capability of easily changing the frequency values and overlapping the bandwidth as well.

During the preliminary flights, stepped frequency technique was not used to increase geometric resolution (in this case a bandwidth overlap would help the processing) but only to produce multilooked images.

The system settings for the different functional modalities are described as follows.

Sounder Mode. Transmitted bandwidth of $10 \mathrm{MHz}$ centered on a $163 \mathrm{MHz}$ carrier. The transmitted signal is generated by FGU as LFM with the starting frequency at $158 \mathrm{MHz}$.

SAR-Low. Stepped $40 \mathrm{MHz}$ transmitted bandwidth synthetized by four subbands of $10 \mathrm{MHz}$ transmitted over four carriers. The carriers differ of $10 \mathrm{MHz}$ each other, thus, no overlap arises between the transmitted subbands. By considering the four frequency subranges, the transmitted signal covers the frequency range (430-470) MHz.

SAR-High. Stepped $80 \mathrm{MHz}$ transmitted bandwidth synthesized by eight subbands of $10 \mathrm{MHz}$ transmitted over eight carriers. The carriers differ of $10 \mathrm{MHz}$ each other, thus, no overlap arises between the transmitted subbands. By considering the four frequency subranges, the transmitted signal covers the overall frequency range (820-900) MHz.

As it can be seen from Figure 2, Tx and Rx blocks are common to either Sounder and Imager operative modes. Only the frequency up conversion modules are different. Tx block performs base band signal generation. The base band signal, as described before, is the Sounder signal itself. The chains depicted in Figure 2, UHF-Low, which means $450 \mathrm{MHz}$ carrier, UHF-High, which means $860 \mathrm{MHz}$ carrier, and VHF band, work in an exclusive way. VHF corresponds to Sounder operative mode and performs base band signal amplification only. UHF-High and UHF-Low blocks perform base band signal upconversion to working frequencies when relatives operational mode are selected. Rx block performs data antialiasing filtering and data sampling after frequency downconversion, taking place into Imager operative modes only.

The designed architecture allows a high flexibility to the system in terms of transmitted bandwidth; in fact, the radar can be easily upgraded to transmit a wider bandwidth.

As regards the Rx chain, after the downconversion is performed in the SAR-Low and SAR-High receiving chains, the IF signal is centered at $163 \mathrm{MHz}$, covering [158-168] MHz bandwidth. Hence, the incoming signal is sampled by the $\mathrm{ADC}$ at $100 \mathrm{MHz}$ using the undersampling technique. In other words, the sampled spectrum is a replica at IF of the main one. This solution ensures the advantage to use the same ADC for different frequency carriers, such as $163 \mathrm{MHz}, 450 \mathrm{MHz}$, and $860 \mathrm{MHz}$, thus allowing a hardware cost saving and avoiding the use of a critical (relative bandwidth approaching to unity) antialiasing filter. An auto check functional mode is implemented so to carry out an internal calibration. Specifically, a high speed and high 
TABLE 2: System parameters.

\begin{tabular}{lccc}
\hline & Sounder & SAR-Low & SAR-High \\
\hline Altitude & $>1300 \mathrm{~m}$ & $>1000 \mathrm{~m}$ & $>1000 \mathrm{~m}$ \\
Carrier & $163 \mathrm{MHz}$ & $450 \mathrm{MHz}$ & $860 \mathrm{MHz}$ \\
Tx bandwidth & $10 \mathrm{MHz}$ & $40 \mathrm{MHz}$ & $80 \mathrm{MHz}$ \\
Tx steps & $1 \times 10 \mathrm{MHz}$ & $4 \times 10 \mathrm{MHz}$ & $80 \mathrm{MHz}$ \\
PRF & $500 \mathrm{~Hz}$ & $2000 \mathrm{~Hz}$ & $4000 \mathrm{~Hz}$ \\
Pulse width (single step) & & $3.3 \mu$ s for all operative modes & $8.03 \mu \mathrm{s}$ \\
Rx window width & $10 \mu \mathrm{s}$ & $8.03 \mu \mathrm{s}$ & Planar array of $2 \times 8$ patch, dual polarization \\
Antenna type & Periodic Log & Planar array of $1 \times 4$ patch & $19 \mathrm{~dB}$ \\
Antenna gain & $7 \mathrm{~dB}$ & $17 \mathrm{~dB}$ & $45^{\circ}$ for both SAR operative mode \\
Elevation pointing & $\mathrm{Nadir}$ & $0^{\circ}$ for both SAR operative mode \\
Azimuth pointing & $\mathrm{Nadir}$ & $75^{\circ}$ & $37^{\circ}$ \\
Range aperture & $68^{\circ}$ & $20^{\circ}$ & $10^{\circ}$ \\
Azimuth aperture & $50^{\circ}$ & $50 \mathrm{MHz} / 100 \mathrm{MHz}$ for all operative mode \\
ADC sampling frequency & & $200 \mathrm{~W}$ for all operative mode & \\
Peak power & & \multicolumn{2}{c}{}
\end{tabular}

TABLE 3: Nominal performances.

\begin{tabular}{lccc}
\hline & Sounder & SAR-Low & SAR-High \\
\hline Across track resolution & $10-100 \mathrm{~m}$ & N/A & N/A \\
Range resolution (free space) & $15 \mathrm{~m}$ & $3.75 \mathrm{~m}$ (stepped) & $1.87 \mathrm{~m}$ (stepped) \\
Along track resolution & $7-75 \mathrm{~m} @ 800 \mathrm{~m}$ & $4.8 \mathrm{~m} @ 4$ looks & $2.5 \mathrm{~m} @ 2$ looks \\
Penetration depth & $27-280 \mathrm{~m} @ 3000 \mathrm{~m}$. & No penetration \\
Maximum swath (geometrical) & $100 \mathrm{~m}$ (moderate attenuation) & Foliage penetration & $1500 \mathrm{~m} @ 1000 \mathrm{~m}$ \\
NESZ & $2000 \mathrm{~m} @ 800 \mathrm{~m}$ & $7400 \mathrm{~m} @ 1000 \mathrm{~m}$ & $-70 \mathrm{~dB}$ \\
AASR & $7000 \mathrm{~m} @ 3000 \mathrm{~m}$ & $-80 \mathrm{~dB}$ & $-54 \mathrm{~dB}$ \\
RASR & $-95 \mathrm{~dB} @ 800 \mathrm{~m}$ & $-64 \mathrm{~dB}$ & No appreciable at chosen PRF \\
\hline
\end{tabular}

attenuation switch reroutes the transmitted signal on the $\mathrm{Rx}$ chain bypassing the antenna. The auto check mode may be switched on, manually, every time during the mission, with the exception of the acquisition stage.

Platform altitude and georeferencing are ensured by external GPS/INS linked by serial port to the RDU.

The nominal parameters of the three radars are listed in Table 2, whereas their performances are summarized in Table 3. Here, the noise equivalent sigma zero (NESZ), azimuth ambiguity ratio (AASR), and range ambiguity ratio (RASR) are also reported.

Three different antennas are adopted: one for the sounder and two for the imager modalities. The sounder antenna is a standard Log periodic with four radiating elements, having a $7 \mathrm{~dB}$ gain, a beam width of $68^{\circ}$, and a front-toback ratio of 15-19 $\mathrm{dB}$. The imager antennas are planar patch arrays designed and realized at the Microwave Laboratory of University of Calabria, Cosenza, Italy. A photo of the sounder and imager SAR-Low antenna installed on the civil helicopter (Eurocopter AS350) used for the surveys is shown in Figure 3.

Both data from the sounder and imager are preprocessed by ad-hoc configurable software. Prior interesting works in the sounder area can be found in [5-7]. Focusing is the core of the data processing and is based on the well assessed Chirp Scaling Algorithm (CSA) [5-15].

Due to Doppler bandwidth oversampling, a data presumming is performed in order to improve the signal to noise ratio. Other preprocessing features are related to interferences identification and suppression [16]. Furthermore, the Phase Gradient Autofocus (PGA) algorithm allows for a motion compensation [17-19]. This last feature is useful in imager data processing. The Doppler parameter estimation is necessary for data processing and is achieved by data together with 


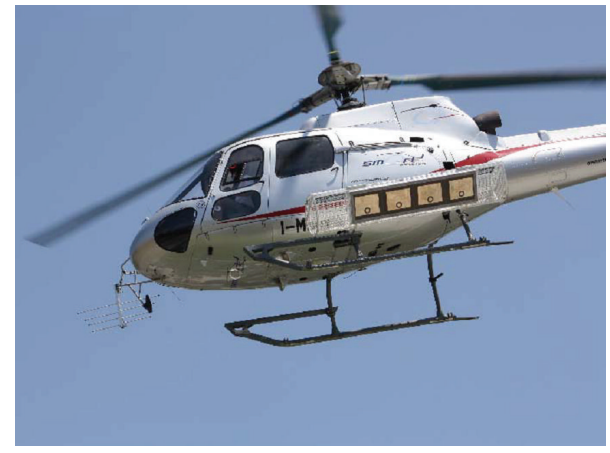

FIGURE 3: Sounder and imager antenna in flight configuration.

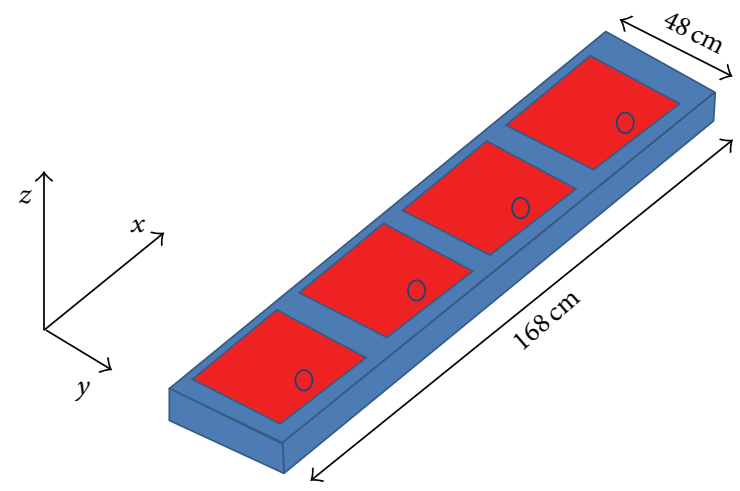

FIGURE 4: SAR antenna configuration.

auxiliary information from the GPS/INS navigation system. The data processing software is developed in Matlab environment. In this context, heritage gained during SHARAD mission has been used, because CO.RI.S.T.A. designed and developed data processing algorithms for this instrument [20]. For what concerns the nadir suppression technique, no particular implementation has been performed at the antenna level, where the reduced number of elements (the minimum one sufficient for the application and giving a compact structure) does not allow an efficient synthesis technique to properly reduce the sidelobes. However, nadir return is cut away from the scene with an appropriate selection of the PRF and the receiving window opening time values.

\section{SAR Antenna: Design and Test}

The antenna configuration adopted for the imager modality SAR-Low is composed of an array of $1 \times 4$ microstrip patches operating in linear vertical polarization (Figure 4). The single radiating element is given by a coaxial fed patch antenna and loaded with a capacitive ring, so to have a compact and wideband antenna [21, 22].

In particular, to realize a large operating bandwidth of about $80 \mathrm{MHz}$, even greater than that required by the

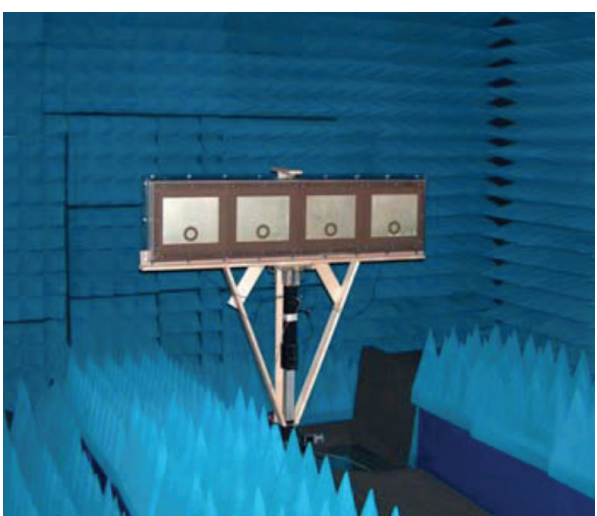

FIgURE 5: SAR-Low antenna mounted into the anechoic chamber at University of Calabria.

application, a foam dielectric $\left(\varepsilon_{r}=1.07\right)$ having thickness equal to $6 \mathrm{~cm}$ is adopted as main substrate, and an upper thin $(0.762 \mathrm{~mm})$ layer of standard dielectric (Arlon Diclad $\left.870, \varepsilon_{r}=2.33\right)$ is inserted uniquely to guarantee a strong mechanical support. This gives a compact single-layer structure, with a strongly reduced thickness (compared to the wavelength), while similar performances are generally achieved by adopting much more complex configurations [23].

A photograph of the SAR-Low array mounted in the anechoic chamber of the Microwave Laboratory at University of Calabria is illustrated in Figure 5. A full experimental characterization of the array, having a weight approximately equal to $4 \mathrm{Kg}$, is performed in terms of both return loss and radiation pattern behavior. In particular, the wideband feature is well confirmed by the return loss illustrated in Figure 6, where a good agreement can be observed between simulations (Ansoft Designer) and measurements.

The measured radiation pattern in the $y=0$ array plane (Figure 4) is reported in Figure 7 for the central design frequency equal to $450 \mathrm{MHz}$. A $-3 \mathrm{~dB}$ beamwidth approximately equal to $22^{\circ}$, as imposed by the constraint on the azimuth resolution, is obtained in the copolar field.

Furthermore, the array shows an excellent performance in terms of cross polar component, which is significantly lower with respect to the copolar one. The radiation performances of the designed array is maintained all over the operating frequency range, as demonstrated by a very similar behavior of the measured radiation patterns at different frequencies, reported in Figure 8. Finally, the measured boresight gain, with a mean value properly equal to $17 \mathrm{~dB}$ (as declared in Table 2), is illustrated in Figure 9. A similar configuration is adopted for the SAR-High antenna, with the same basic radiating element, but working at dual linear polarization and assuming an array of $2 \times 8$ elements in order to increase the azimuth resolution.

A design very similar to that adopted in the case of SARLow antenna is assumed, but including two coaxial feeds, in order to have the dual polarization feature. A foam thickness equal to $3 \mathrm{~cm}$, with an upper thin $(0.762 \mathrm{~mm})$ layer of Arlon Diclad 870 is considered, and the overall dimension of the 


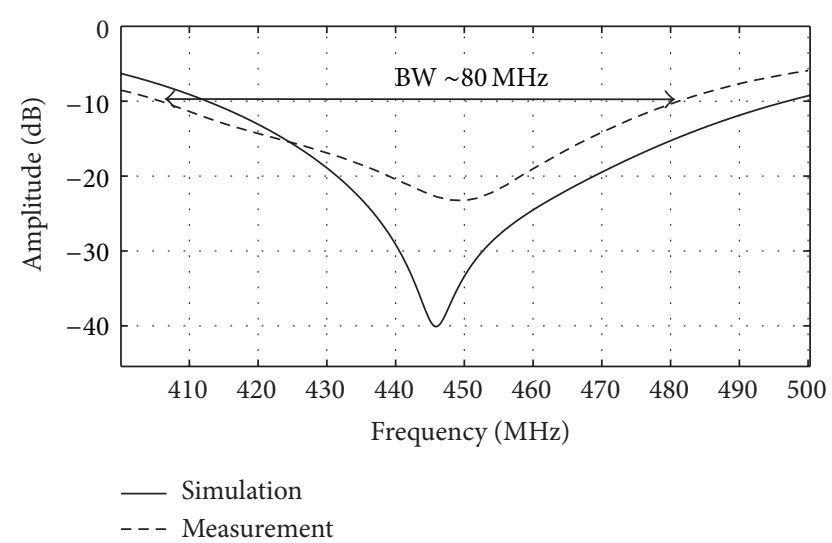

FIGURE 6: Return loss of SAR-Low antenna: comparison between simulation and measurement.

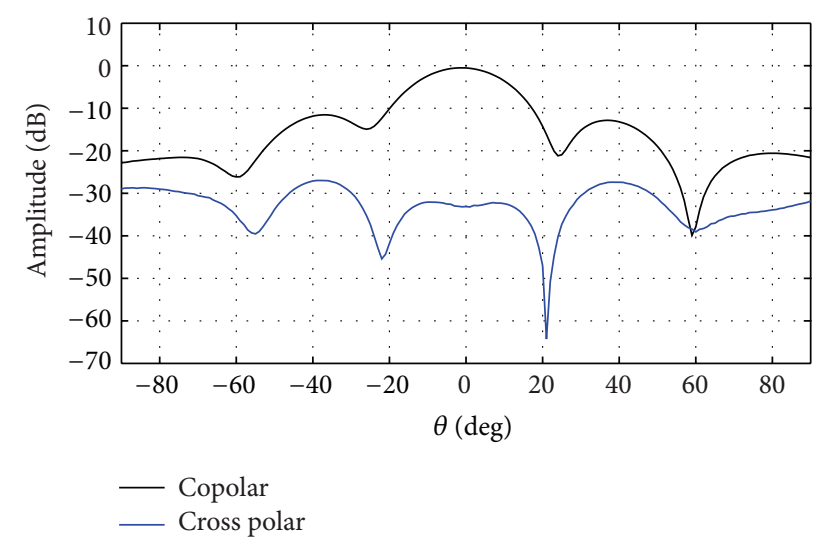

FIGURE 7: Measured radiation pattern of SAR-Low antenna: copolar and cross polar components @ $450 \mathrm{MHz}$.

SAR-High array is exactly equal to that relative to the SARLow case (Figure 4), so to adopt the same equipped slot on the helicopter. Experimental validations are again performed into the Microwave Laboratory at University of Calabria (Figure 10).

In particular, the return loss curves, reported in Figure 11, show a very similar behavior for the two linear polarizations, with an operating bandwidth approximately equal to $120 \mathrm{MHz}$, again greater than that imposed by the application. The measured pattern in the $y=0$ array plane reported in Figure 12 for the central frequency of $900 \mathrm{MHz}$. A $-3 \mathrm{~dB}$ beamwidth approximately equal to $12^{\circ}$, as imposed by the constraints on the azimuth resolution, can be observed in the copolar field, significantly above $(\sim 25 \mathrm{~dB})$ the undesired cross polar component. Finally, the measured gain (at boresight) for the two polarizations, reported in Figure 13, show a mean value approximately equal to $19 \mathrm{~dB}$, as indicated in Table 2 .

\section{Measurement Campaign Results}

Two flight campaigns are performed with the aim to verify system functionality in operative conditions. Only the sounder antenna is mounted on board of a military helicopter

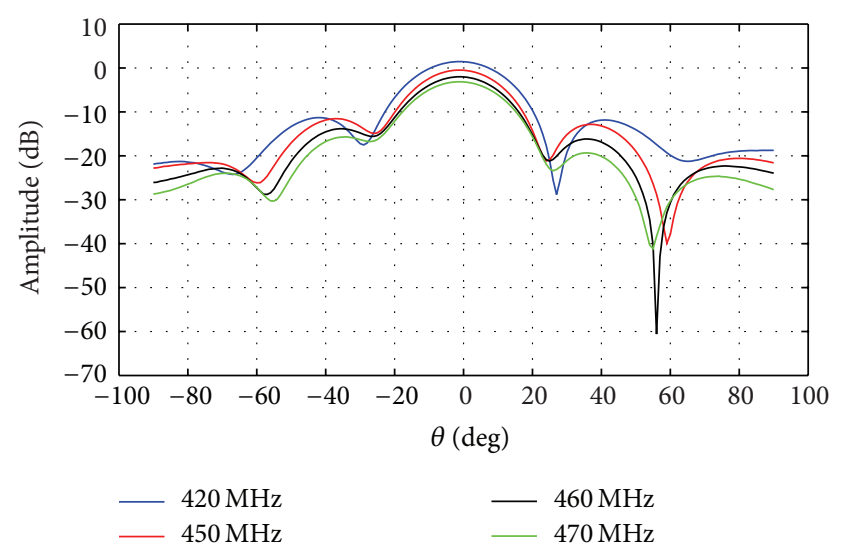

FIGURE 8: Measured radiation pattern of SAR-Low antenna: copolar component at different frequencies.

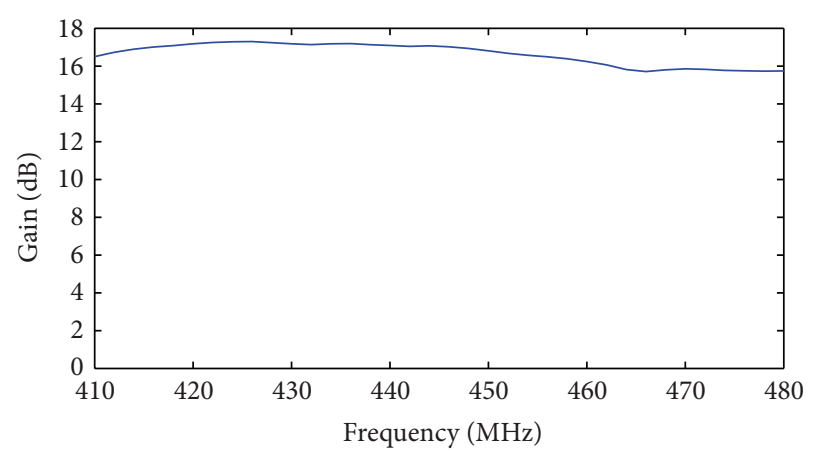

FIGURE 9: Measured gain of SAR-Low antenna versus frequency at boresight.

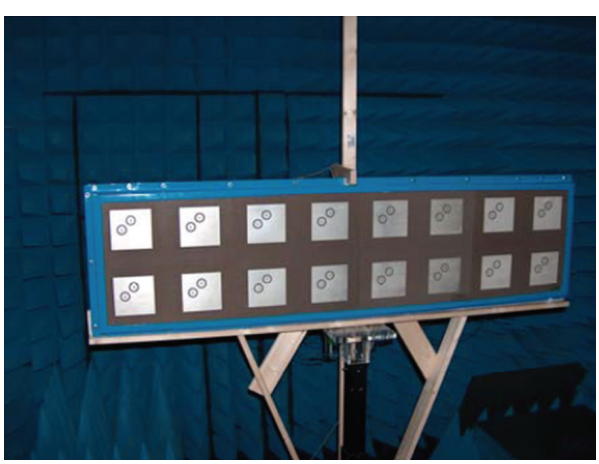

FIGURE 10: SAR-High antenna mounted into the anechoic chamber at University of Calabria.

during the first flight campaign. The relative performed tracks over an ancient volcanic hill located in the Roccamonfina site (South Italy) are reported in Figure 14, while the obtained radargram is shown in Figure 15. By observing the Figures, there are some evidence that the sounder is able to penetrate the hill terrain and intercept the bedrock at about $300 \mathrm{~m}$ depth.

During the second flight campaign, the $450 \mathrm{MHz}$ antenna is also mounted on board of a commercial helicopter. An 


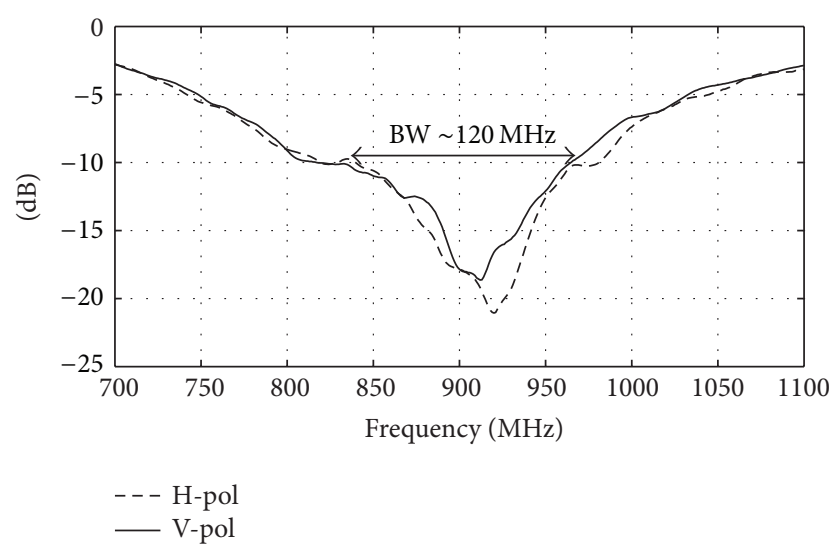

FIGURE 11: Return loss of SAR-High antenna: comparison between $\mathrm{H}$ and $\mathrm{V}$ polarizations.

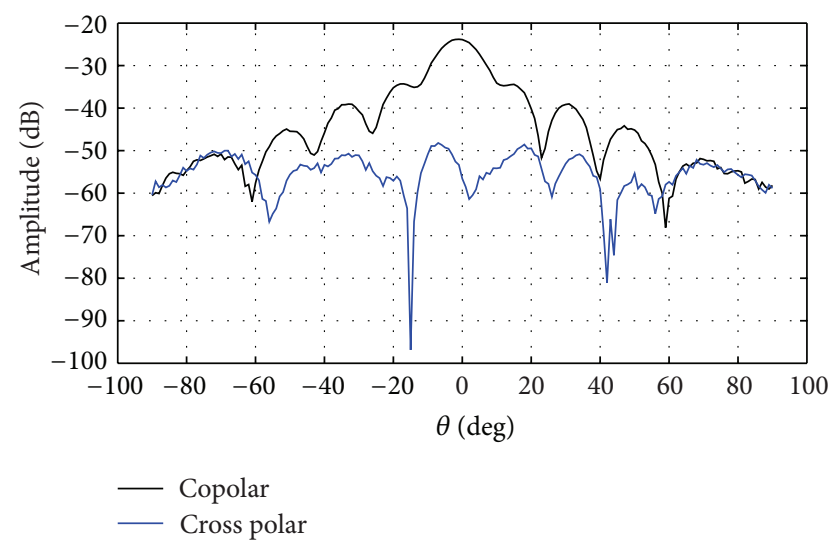

FIGURE 12: Measured radiation pattern of SAR-High antenna: copolar and cross polar components @ $900 \mathrm{MHz}$.

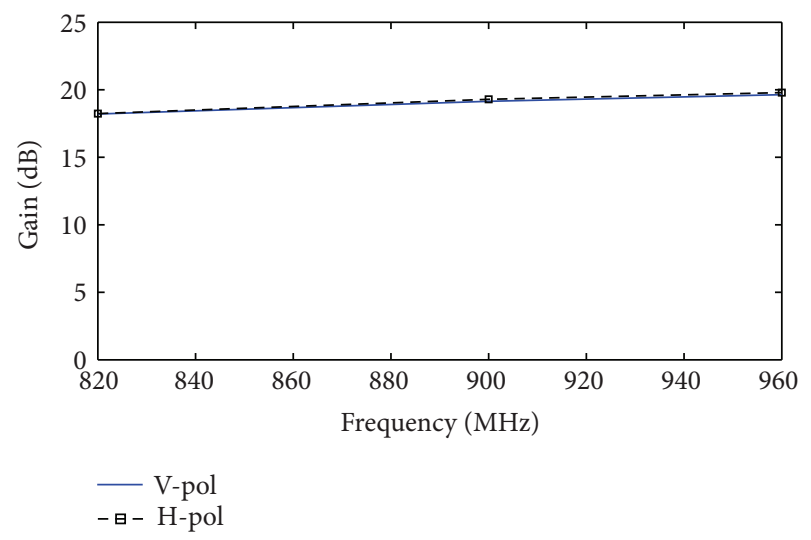

FIGURE 13: Measured gain of SAR-High antenna versus frequency at boresight: comparison between $\mathrm{H}$ and $\mathrm{V}$ polarizations.

example of the resulting SAR image over a coastal zone in Southern Italy (Paestum) is illustrated in Figure 16.

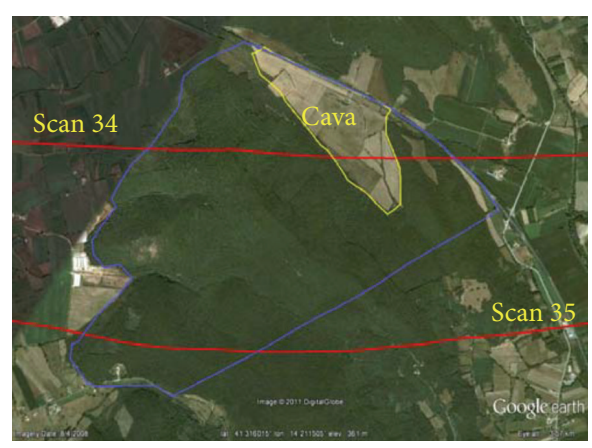

FIgURE 14: Performed tracks over an ancient volcanic hill located in the Roccamonfina site (South Italy).

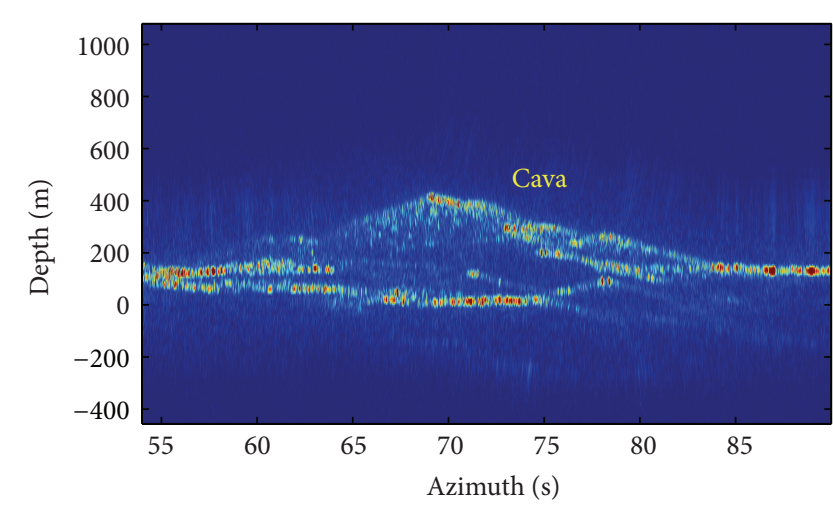

FIGURE 15: Obtained radargram on the Roccamonfina site (South Italy).

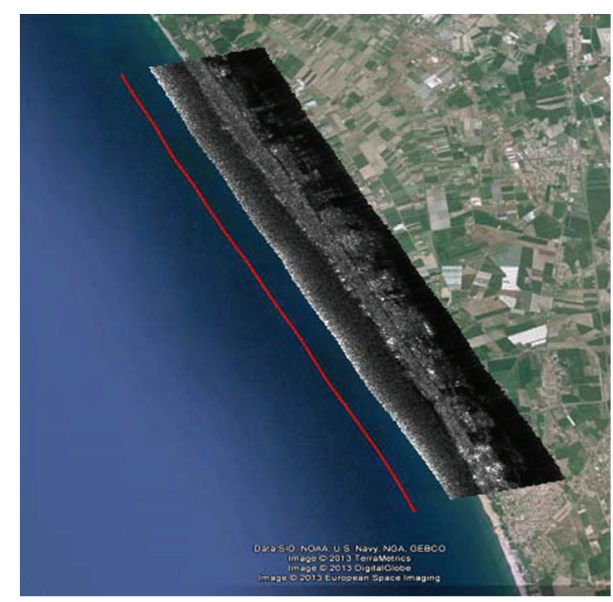

FIGURE 16: SAR image obtained over a coastal zone in Southern Italy (Paestum).

\section{Conclusions and Future Works}

The design of a flexible and low-cost airborne radar, able to easily switch between different operational modes (sounder as well as SAR imager) has been fully described in this work. The availability of more different frequency bands packaged into a unique system makes it strongly useful to obtain maps 
with different penetration depths, thus specifically powerful in tomographic applications, as demonstrated by the first measurement campaigns. Actually, only two flight validations have been performed with the aim of verifying the overall system functionality.

No calibration flights have been performed to assess the true system performances, and this will be the focus of a future work. Furthermore, even if the proposed radar is conceived to be fully polarimetric, it is not currently equipped to receive the two polarizations simultaneously, because it contains only one receiving channel. Therefore, the full polarization can only be implemented in an "interleaved" configuration, that is, through 4 consecutive pulses $(\mathrm{HH}, \mathrm{HV}$, $\mathrm{VH}$, and VV). The receiving channel duplication will be an upgrade foreseen in the next future.

\section{Conflict of Interests Disclosure}

We state there is no financial or competing interest which could influence the validity of the present research.

\section{Acknowledgment}

The authors would like to thank Mr. Ennio Marozzo for the precious technical support in the realization of the antenna prototypes.

\section{References}

[1] H. Hellsten, L. M. Ulander, A. Gustavsson, and B. Larsson, "Development of VHF CARABAS II SAR," in Radar Sensor Technology, vol. 2747 of Proceedings of SPIE, pp. 48-60, April 1996.

[2] E. G. Njoku, W. J. Wilson, S. H. Yueh et al., "Observations of soil moisture using a passive and active low-frequency microwave airborne sensor during SGP99," IEEE Transactions on Geoscience and Remote Sensing, vol. 40, no. 12, pp. 26592673, 2002.

[3] G. Smith-Jonforsen, L. M. H. Ulander, and X. Luo, "Low VHPband backscatter from coniferous forests on sloping terrain," IEEE Transactions on Geoscience and Remote Sensing, vol. 43, no. 10, pp. 2246-2260, 2005.

[4] L. M. H. Ulander, M. Lundberg, W. Pierson, and A. Gustavsson, "Change detection for low-frequency SAR ground surveillance," IEE Proceedings: Radar, Sonar and Navigation, vol. 152, no. 6, pp. 413-420, 2005.

[5] M. E. Peters, D. D. Blankenship, S. P. Carter, S. D. Kempf, D. A. Young, and J. W. Holt, "Along-track focusing of airborne radar sounding data from west antarctica for improving basal reflection analysis and layer detection," IEEE Transactions on Geoscience and Remote Sensing, vol. 45, no. 9, pp. 2725-2736, 2007.

[6] R. Scheiber, P. Prats, and F. Hélière, "Surface clutter suppression techniques for ice sounding radars: analysis of airborne data," in Proceedings of the 7th European Conference on Synthetic Aperture Radar (EUSAR '08), pp. 1-4, Friedrichshafen, Germany, June 2008.
[7] K. C. Jezek, S. Gogineni, X. Wu et al., "Two-frequency radar experiments for sounding glacier ice and mapping the topography of the glacier bed," IEEE Transactions on Geoscience and Remote Sensing, vol. 49, no. 3, pp. 920-929, 2011.

[8] K. Player, L. Shi, C. Allen et al., "A multi-channel depthsounding radar with an improved power amplifier," HighFrequency Electronics, pp. 18-29, 2010.

[9] F. Rodriguez-Morales, P. Gogineni, C. Leuschen et al., "Development of a multi-frequency airborne radar instrumentation package for ice sheet mapping and imaging," in Proceedings of the IEEE MTT-S International Microwave Symposium (MTT '10), pp. 157-160, Anaheim, Calif, USA, May 2010.

[10] L. Shi, C. T. Allen, J. R. Ledford et al., "Multichannel coherent radar depth sounder for NASA operation ice bridge," in Proceedings of the 30th IEEE International Geoscience and Remote Sensing Symposium (IGARSS '10), pp. 1729-1732, Honolulu, Hawaii, USA, July 2010.

[11] L. M. H. Ulander, B. Flood, P. O. Frolind et al., "Bistatic VHF/UHF-band airborne SAR experiment," in Proceedings of the IET International Conference on Radar Systems (Radar '12), pp. 22-25, Glasgow, UK, October 2012.

[12] A. Potsis, A. Reigber, and K. P. Papathanassiou, "Phase preserving method for RF interference suppression in P-band synthetic aperture radar interferometric data," in Proceedings of the IEEE International Geoscience and Remote Sensing Symposium (IGARSS '99), pp. 2655-2657, Hamburg, Germany, July 1999.

[13] J. Dall, "A new frequency domain autofocus algorithm for SAR," in Proceedings of the International Geoscience and Remote Sensing Symposium (IGARSS '91), pp. 1069-1072, Helsinki, Finland, June 1991.

[14] Y. Zhang, J. Wu, and H. Li, “Two simple and efficient approaches for compressing stepped chirp signals," in Proceedings of the Asia-Pacific Microwave Conference (APMC '05), vol. 1, pp. 690693, Suzhou, China, December 2005.

[15] G. I. Cumming and H. F. Wong, Digital Processing of Synthetic Aperture Radar Data, Artech House, Boston, Mass, USA, 2005.

[16] J. C. Curlander and R. N. McDonough, Synthetic Aperture Radar, John Wiley \& Sons, New York, NY, USA, 1991.

[17] A. Moreira, J. Mittermayer, and R. Scheiber, "Extended chirp scaling algorithm for air- and spaceborne SAR data processing in stripmap and ScanSAR imaging modes," IEEE Transactions on Geoscience and Remote Sensing, vol. 34, no. 5, pp. 1123-1136, 1996.

[18] A. Moreira and Y. Huang, "Airborne SAR processing of highly squinted data using a chirp scaling approach with integrated motion compensation," IEEE Transactions on Geoscience and Remote Sensing, vol. 32, no. 5, pp. 1029-1040, 1994.

[19] A. Gallon and F. Impagnatiello, "Motion compensation in chirp scaling SAR processing using phase gradient autofocusing," in Proceedings of the IEEE International Geoscience and Remote Sensing Symposium (IGARSS '98), pp. 633-635, Seattle, Wash, USA, July 1998.

[20] G. Alberti, S. Dinardo, S. Mattei, C. Papa, and M. R. Santovito, "SHARAD radar signal processing technique," in Proceedings of the 4th International Workshop on Advanced Ground Penetrating Radar (IWAGPR '07), pp. 261-264, Naples, Italy, June 2007.

[21] S. Costanzo and A. Costanzo, "Compact slotted antenna for wideband radar applications," in Advances in Information Systems and Technologies, Á. Rocha, A. M. Correia, T. Wilson, and K. A. Stroetmann, Eds., vol. 206 of Advances in Intelligent Systems and Computing, pp. 989-996, 2013. 
[22] S. Costanzo and A. Costanzo, "Compact U-slotted antenna for broadband radar applications," Journal of Electrical and Computer Engineering, vol. 2013, Article ID 910146, 6 pages, 2013.

[23] S. López-Peña, J.-F. Zürcher, R. Torres, A. G. Polimeridis, and J. R. Mosig, "Modeling and manufacturing of a series of identical antennas for a P-Band ice sounder," in Proceedings of the 4th European Conference on Antennas and Propagation (EuCAP '10), Barcelona, Spain, April 2010. 

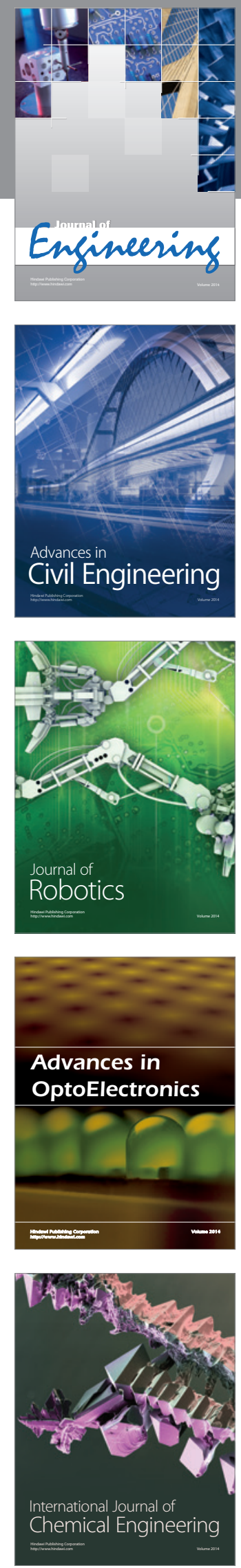

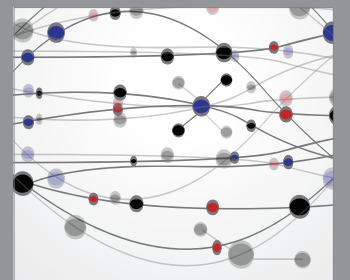

The Scientific World Journal
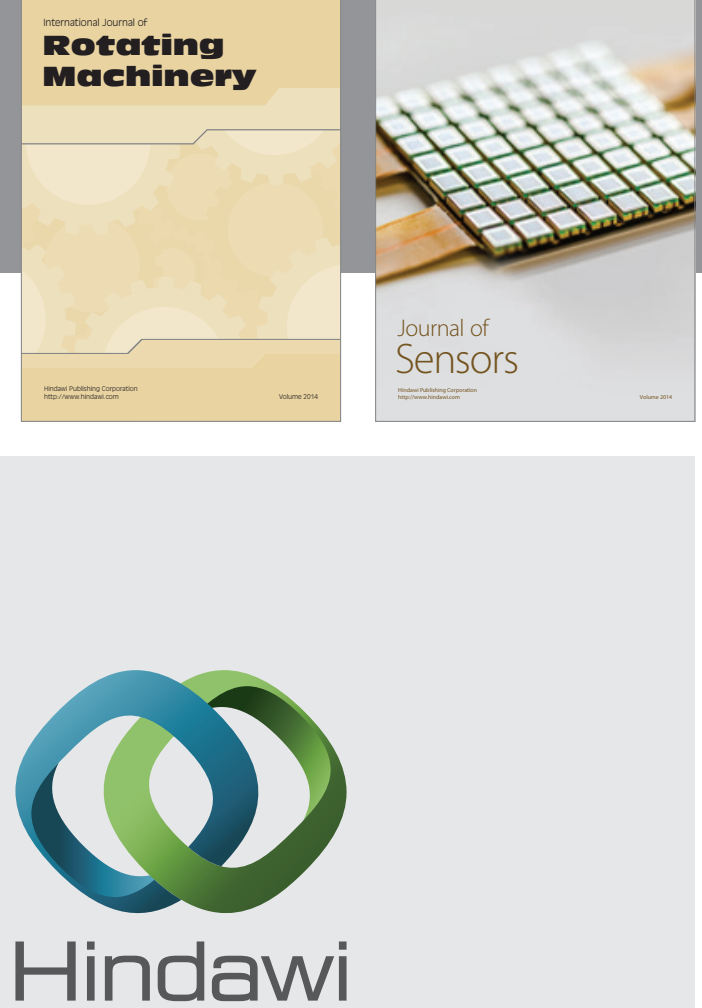

Submit your manuscripts at http://www.hindawi.com
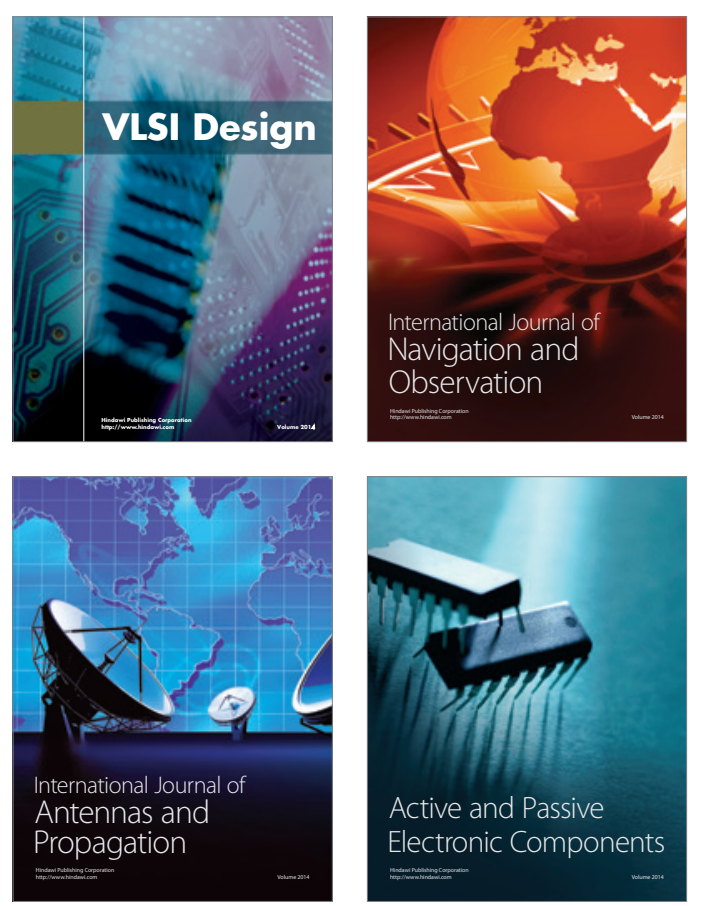
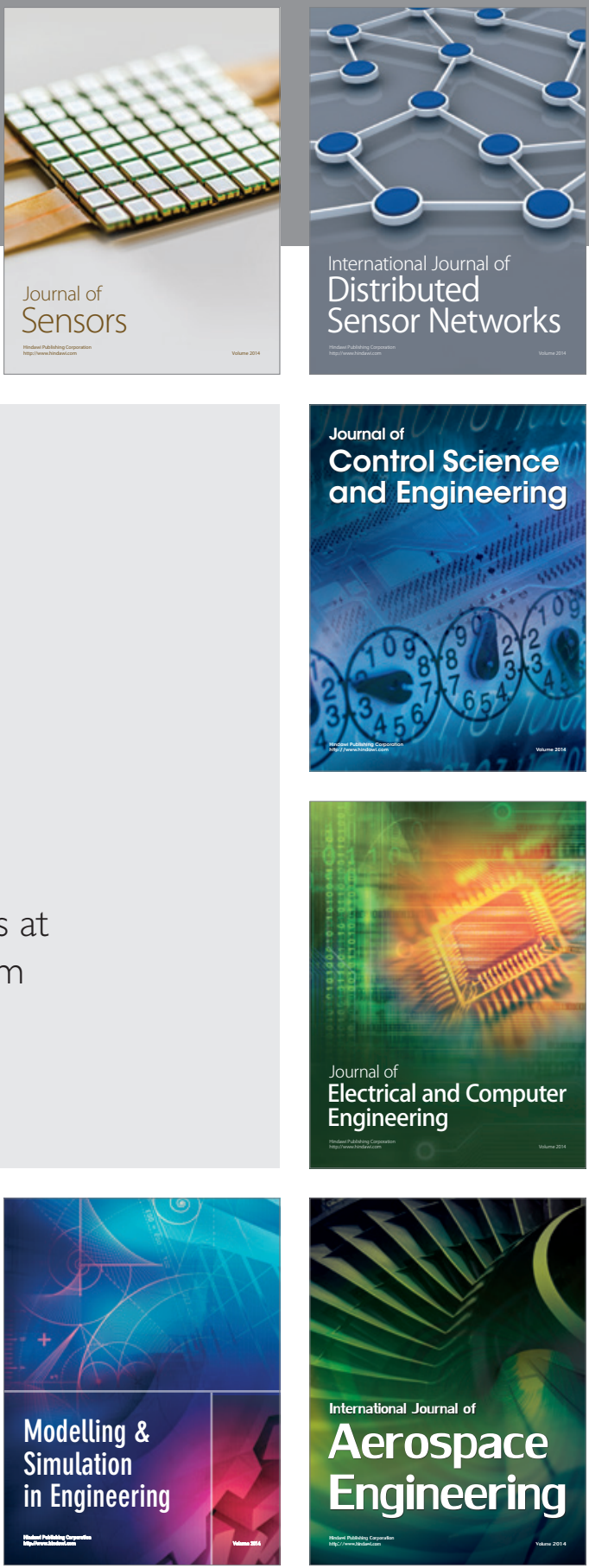

Journal of

Control Science

and Engineering
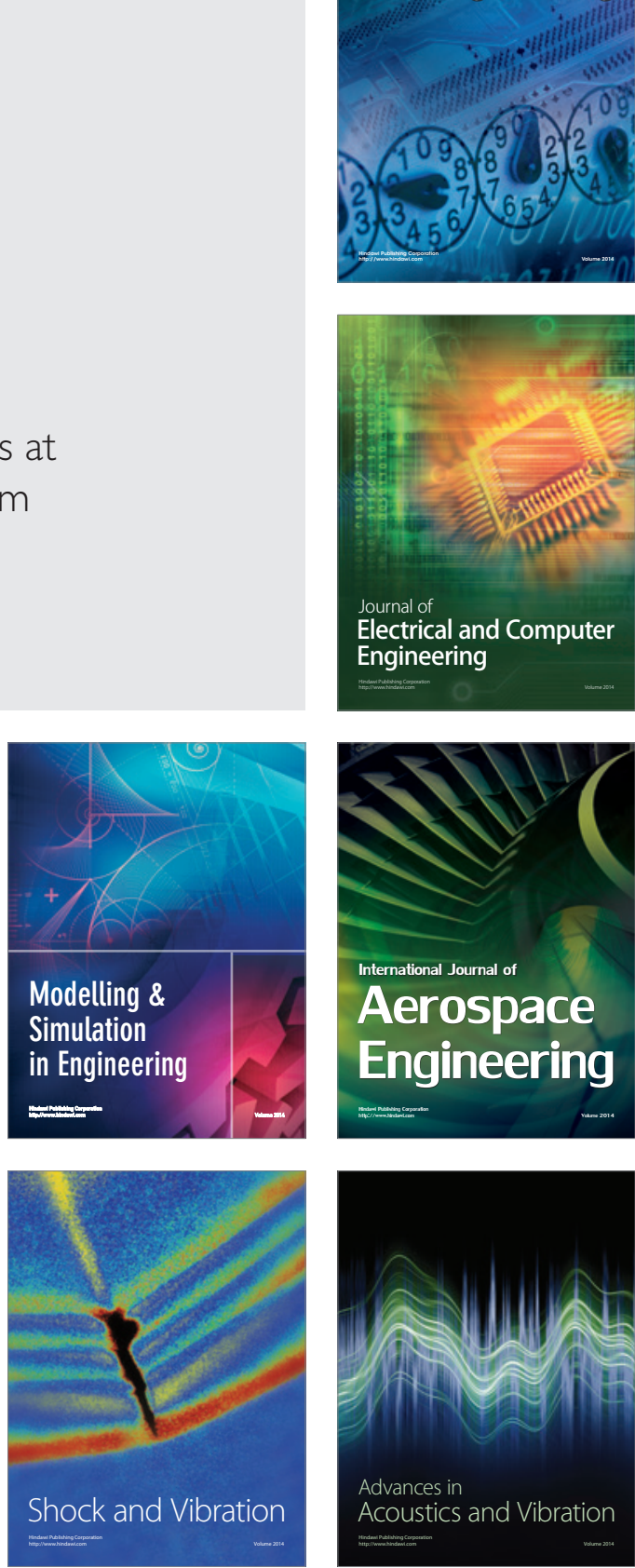